\title{
Nuclear Energy in Ghana? History, Science and Policy
}

\author{
Samuel Adu-Gyamfi*, Kwasi Amakye-Boateng, Edward Brenya, Henry Tettey Yartey, \\ Aminu Dramani, Victor Nii Adoteye \\ Kwame Nkrumah University of Science and Technology, Kumasi, Ghana \\ *mcgyamfi@yahoo.com
}

\begin{abstract}
This paper discusses the issue of nuclear energy in Ghana, although the country is not operating a nuclear plant, the study focuses on the energy crisis that persistently hit the country and government's plans to opt for nuclear energy as part of Ghana's energy's mix to cater for the shortfalls in Ghana's electricity generation. Ghana after independence decided to add nuclear energy into its energy mix to promote industrialization and make Ghana an industrial hub and investment destination as well as make it a net exporter of power in Africa. In spite of this plan for a nuclear plant resurfacing within contemporary discourse, there has been a strong opposition against the country going nuclear, citing some safety and security issues which are sometimes fueled by lack of an in depth knowledge of what nuclear energy really entails. Qualitative research approach was employed to investigate Ghana's drive for attaining its initial plans for a nuclear plant. Data has been retrieved from both primary and secondary sources. The analysis of the data collected revealed that Ghana's inability to operate a nuclear plant is as a result of fear of a nuclear disaster like it happened at Three Mile Island in Pennsylvania, USA, Chernobyl in Ukraine and Fukishima Daichi in Japan, as well as the safety of the nuclear plants and the radioactive wastes emitted into the environment. The study revealed that this fear of people regarding nuclear energy is over-emphasized and again the major nuclear disasters that have rocked the world were caused by human error; in most cases security warnings were ignored. The study established that the delay in executing the plans are due to monetary challenges since building a nuclear plant involves a lot of money. This notwithstanding, Ghana has enough skilled nuclear scientists to manage the country's nuclear plants should any be built.
\end{abstract}

\section{Keywords: Nuclear Energy, Policy, Government, Public Perception, Ghana}

\section{Introduction}

It is human nature to test, to observe and to dream. The history of nuclear energy is the story of a centuriesold dream becoming a reality. Ancient Greek philosophers first developed the idea that all matter is composed of invisible particles called atoms. The word atom comes from the Greek word, atomos, meaning indivisible. Scientists in the eighteenth and nineteenth centuries revised the concept based on their experiments. By 1900, physicists knew the atom contains large quantities of energy. British physicist Ernest Rutherford was called the father of nuclear science because of his contribution to the theory of atomic structure (US Department of Energy, 2017). Man decided to discover new methods of energy generation and nuclear energy happens to be one of such methods sought by man. According to Ernest Rutherford, the father of nuclear science, "if it were ever possible to control at will the rate of disintegration of the radio elements, an enormous amount of energy could be obtained from a small amount) of matter" (Ledoshchuk, 2016). Prior to the discovery of nuclear energy, there were some ground-breaking discoveries into some components of nuclear energy development which later resulted in the eventual discovery of nuclear energy. In 1898, French physicist Pierre Curie and his wife Maria Sklodowska-Curie had discovered what they will name as radium (Ledoshchuk, 2016). In 1917, Ernest Rutherford the father of nuclear physics was credited with splitting the atom. In 1932, John Cockcroft and Ernest Walton attempted to split the atomic nucleus thereby producing two helium nuclei (Ledoshchuk, 2016). Also, in 1932 James Chadwick discovered the neutron. In 1934 nuclear fission was first experimentally achieved by Enrico Fermi in Rome, when his team bombarded uranium with neutrons. In 1938, German chemists Otto Hahn and Fritz Strassmann, along with Austrian physicists Lise Meitner and Otto Robert Frisch, conducted experiments with the products of neutronbombarded uranium (Ledoshchuk, 2016). All of these were precursors to the whole construct of nuclear energy. After all, these discoveries were made before utilization began.

It is reported that the first nuclear reactors were all designed to produce plutonium for their respective nuclear weapons programs (Walls and Harrison, 2011). Earliest atomic research focused on developing an effective weapon for use in World War II. The work was done under the code name Manhattan Project (US 
Department of Energy, 2017). Early in 1942, a group of scientists led by Fermi gathered at the University of Chicago to develop their theories. By November 1942, they were ready for construction to begin on the world's first nuclear reactor, which became known as Chicago Pile1 (US Department of Energy, 2017). The US Department of energy reports that the major goal of nuclear research in the mid-1950s was to show that nuclear energy could produce electricity for commercial use. The first commercial electricity-generating plant powered by nuclear energy was located in Shipping port, Pennsylvania. It reached its full design power in 1957 (US Department of Energy, 2017). Nuclear energy then became the epitome of modernity in the 1950s and 1960s and seemed to have promised abundant energy even in the 1970s. Significantly, the accidents at Three Mile Island and Chernobyl halted development in almost all countries. Some plants were decommissioned before the end of the intended life span. However, instead of building new reactors, existing ones have been upgraded and their licenses extended, thus offering almost new reactors. The last decade has seen a renewed interest in nuclear energy, with a new generation of fission reactors (relying on existing reactor experience and adding more automatic safety systems, e.g.) entering the scene (Grandin, Jagers and Kullander, 2010).

Grandin, Jagers and Kullander (2010) have argued that electricity was generated for the first time by a nuclear reactor on December 20, 1951, at the EBR-I experimental station near Arco, Idaho, which initially produced about $100 \mathrm{~kW}$ (the Arco Reactor was also the first to experience partial meltdown, in 1955). Russia's first nuclear power plant and the first in the world to produce electricity, was the 5 MWE Obninsk reactor, in 1954 (Grandin, Jagers and Kullander, 2010). The large scale use of nuclear power during the 1950s and 1960s was concentrated in the USA, UK, Russia and Canada. It was touted as a solution to the urban pollution caused primarily by coal-fired power stations. As a result, the federal government financed and built a number of demonstration reactors to prove to the Energy companies that nuclear was feasible (Walls and Harrison, 2011). The Oil crisis of the 1970s necessitated a focal attention on the nuclear industry. The OPEC oil crises of 1973-1974 caused the prices of oil to soar and made energy independence and energy security focal policy issues on the global stage. The oil crisis among other related issues increased nuclear plant orders as was seen in France, Belgium, Sweden, Japan and the USSR. A total of 423 nuclear reactors were built from 1966 to 1985 (Walls and Harrison, 2011). The US Energy Department has further reported that the nuclear power industry in the U.S. grew rapidly in the 1960s. Utility companies saw this new form of electricity production as economical, environmentally clean and safe. In the 1970s and 1980s, however, growth slowed. Demand for electricity decreased and concern grew over nuclear issues, such as reactor safety, waste disposal and other environmental considerations. Still the U.S. had twice as many operating nuclear power plants as any other country in 1991. This was more than one-fourth of the world's operating plants. Nuclear energy supplied almost 22 percent of the electricity produced in the U.S (US Energy Department, 2017). In many countries, among which is the Netherlands, the use of nuclear energy is a controversial issue. The actions in favor of and against the use of nuclear energy have strongly guided political decision making throughout the years. The first commercial nuclear plant in the Netherlands, Dodewaard, was shut down in 1997 after only 28 years of service (de Groot et al., 2010).

Palliser (2012) has argued that to address energy and climate concerns, the use of non-renewable and renewable energy sources (hydropower, solar, wind, geothermal, biomass) is being analyzed; interest in nuclear power has increased, with proposed government-backed loans to support the building of new plants. Both the Obasanjo (1999-2007) and Yar'Adua's administrations in Nigeria looked to nuclear power as a potential solution to the country's energy woes. Although the government of Nigeria has explored the possibility of developing nuclear energy since the 1970s, there has been renewed interest in nuclear power over the past years (Lowbeer-Lewis, 2011). In 1961, the government of the first Republic of Ghana initiated the Kwabenya Nuclear Reactor Project (KNRP). A 2 MW Soviet Reactor was to be acquired and used for research, training and production of radioisotopes. The objectives of KNRP initiative of 1961 were to: introduce nuclear science and technology into Ghana, develop the infrastructure for nuclear power programme and acquire nuclear technology to provide sufficient electricity for industrialization. The Nuclear Reactor Project was cancelled in 1966 after a military coup (Nyarko, Akaho, and Enninson, 2009). Ghana gained her independence in the same year as the first commercial power plant was built that is, in 1957. Ghana is signatory to the non-proliferation treaty and this allows her to utilize nuclear technology for peaceful purposes. The first president of the country cut the sod for the Ghana Nuclear Reactor Project (GNRP) on 25th November 1964. The project was intended to introduce nuclear science and technology into 
the country and to exploit the peaceful applications of nuclear energy for national development. The Kwabenya Nuclear Reactor Project was abandoned after the first president was removed from power in 1966 through a military coup d'état (Nyarko, Akaho, and Enninson, 2009).

The concern for Ghana deciding to go for nuclear energy has been in the news headlines since 2008. Few questions raised from these concerns include how prepared is Ghana and how will the Ghana Atomic Energy Commission (GAEC) and the government deal with the waste from the nuclear plant in order not to cause harm to the people. It is however reported that concerns regarding nuclear power risks are misconceptions and exaggerations which are largely fueled by international politics. Never have such risks prevented the developed countries from developing nuclear technology (Klutse, 2016). Nuru (2014) has however, emphasized that if there is any issue in the world that has a major problem with its image, then, it must be nuclear energy. Regardless of its enviable track record in terms of safety among all sources of energy, nuclear energy often remains at the bottom in all public opinion ratings primarily due to sheer misconceptions about its nature orchestrated by nuclear antagonists (Nuru, 2014). Ghana is planning to build a nuclear plant for much-needed power generation. Not everyone, however, is in support of the nuclear project which would take eight years to complete. The country generates power from thermal and other sources but they have become unreliable due to increased demand for home and industrial use (Trade News, 2016). The single source of natural gas supply through the West African Gas Pipeline (WAGP) is not reliable since the source and the pipeline system have suffered disruptions in the immediate past either through marine accidents or sabotage. In the midst of these uncertainties, nuclear power could provide at least $10 \%$ of the installed capacity by 2020 (Nyarko, Akaho and Enninson, 2009). It is reported that in 2007, when the third major energy crisis occurred in Ghana, difficulties to raise funds to procure light crude oil for thermal power generation to meet the shortfall in the face of high crude oil prices and delays in the West African Gas pipeline project brought the consideration of nuclear energy for electricity generation to the fore (Birikorang et al., 2012). Although some major research namely the works or writings of scholars such as Nana Ama Browne Klutse (Adding Nuclear Power to Ghana's Energy Mix), Nyarko et al. (Nuclear Power for Electricity Generation in Ghana: Issues and Challenges) and S.A. Birikorang et al. (Prospects of Nuclear Power Today as Part of Ghana Energy Mix and Socio-Economic Development), have focused on the prospects of Nuclear Energy for the generation of electric power for Ghana; little or null interdisciplinary and systematic historical research have been done to highlight the evolution of nuclear energy and the Ghanaian story in particular. In particular, the prospects it holds for the country now and the future needs further amplification.

We have focused on building a narrative from in-depth oral interviews from experts in the field (Ghana Atomic Energy Commission) and written data. They helped us gather enough information on the whole concept of nuclear energy in Ghana and the issues surrounding it. Again, some specific data from these sources included those that concern the contribution of Nkrumah's government and the plans to develop nuclear energy in Ghana. The objective of this paper, however, is to study the history of nuclear energy in Ghana, and to highlight some aspects of policies and the benefits the country stands to gain as well as possible challenges. Based on these objectives, the following research questions have been framed to guide the discussions that shall ensue: What is nuclear energy? What is the history and significance of nuclear energy? Why did Ghana plan and continues to plan a nuclear programme? Are the institutions well-equipped for this task? The paper comprises of five sections. The first section introduces the subject matter, and approaches. The second section pays attention to nuclear energy: the case thus far. We build on the writings of other scholars regarding nuclear energy to weave a tapestry of nuclear energy from past to present. The third section discusses the nuclear energy situation in Ghana; the fourth presents the data collected and analysis of this data. The final section deals with the conclusion of the study which highlights key issues arising out of the research.

Discussions: This section pays attention to the discussions on key issues pertaining to nuclear energy, its history, science and policy focusing attention on the Ghanaian case.

Nuclear Energy: The Case Thus Far: This section of the paper focuses on the review of key definitional, historical and policy issues that have been put out by related literature or authors. We aim at adding to the existing literature or confirm them upon establishing a hiatus among other things. 
What is Nuclear Energy? Hubert (1956) argued that Nuclear Energy is generated from the reactions of nuclear fission materials, thus its definition or description stems from these reactions. He explained the basic elements of nuclear power reactions which formed the basics of nuclear energy. He explained fissionable elements which comprise two isotopes of uranium, U-235 and U-233 and one of plutonium, Pu-239. Of these, only one, U-235, occurs naturally and other two are man-made, $\mathrm{Pu}-239$ which is derived by a radioactive transformation from U-238 and U-233 from thorium. The isotopes, U-235, U-233 and Pu-239 are known accordingly as fissionable or fuel materials. From these materials comes the core of nuclear power reactions and eventual generation of nuclear energy (Hubert, 1956). After outlining the fissionable materials primarily used to produce or generate nuclear energy, Hubert (1956) speaks briefly about the preliminary stages these fissionable materials are subjected to as well as the processes involved in the fission. He explained that the Spontaneous fusion of U-235 occurs when a concentration of this isotope greater than some critical amount is brought together. If the reaction is uncontrolled, the result is the explosion of an atomic bomb; if properly controlled, the energy, in the form of heat, can be released at a determinate rate. Nuclear piles comprise assemblages of fissionable and auxiliary materials for maintaining controlled nuclear reactions (Hubert, 1956).

According to Hubert (1956), when a U-235 atom is struck by a neutron, it breaks into fragments known as fission products which consist of other atoms near the middle of the table of atomic numbers, and also releases neutrons which strike other U-235 atoms, thereby maintaining a chain reaction. Where each fission releases, on the average, 200-million electron volts of heat which like the heat of combustion of coal or oil, can be used to drive a steam power plant. Energy is released by the fusioning of a given amount of uranium (or thorium). The fusioning of 1 gram of U-235 releases $2.28 \times 10^{4} \mathrm{kw}$-hr of heat, which is equivalent to the heat of combustion of 3 tons of coal or 13 barrels of oil. One pound of U-235 is equivalent to 1400 tons of coal or 6000 barrels of oil. Within narrow limits the same values are valid for U-238 and for thorium (Hubert, 1956). In another sense, nuclear power could be defined from a different perspective as power produced from controlled (that is, non-explosive) nuclear reactions. Commercial plants in use to date use nuclear fission reactions. Electric utility reactors heat water to produce steam, which is then used to generate electricity (Ledoshchuk, 2016). In discussing nuclear energy, Janna Palliser talks about the nuclear plant which is the main engine through which electricity is generated from nuclear energy. Nuclear plants use uranium (uranium-238 and uranium-235) in the form of solid ceramic pellets packaged into long, vertical tubes. The pellets are bombarded with neutrons, causing the uranium atoms to split (fission) and release heat and neutrons. These neutrons collide with other uranium atoms and release additional heat and neutrons in a chain reaction. The heat is used to generate steam, which is used by a turbine to generate electricity (Palliser, 2012). Nuclear power is any nuclear technology designed to extract usable energy from atomic nuclei via controlled nuclear reaction (Birikorang et al., 2012).

The History and Significance of Nuclear Energy: One important aspect of nuclear energy is radioactivity; the elements that constitute nuclear energy have radioactive properties and for this reason one of these radioactive materials, uranium, was discovered by Antoine Henri Becquerel who was a French scientist. This element is a vital part of any nuclear power structure. Other scientists apparently from the same country made a groundbreaking discovery which gave rise to other discoveries in similar fields. This couple was Marie Curie and her husband Pierre Curie who were among the first researchers who began to work in the new field of radioactivity. Their discovery won them a Nobel Peace Prize. Soon after Becquerel's contribution, J. J. Thompson discovered the electron in 1897 (Woolbright, Schumacher and Michonova-Alexova, 2014). Presently considered the father of nuclear physics, Ernest Rutherford, a physicist from New Zealand who was one of J. J. Thompson's first students, was the first to formulate the concept of radioactive half-life. He first named and classified alpha, beta and gamma radiation, and verified that radioactivity involved the change of one element into another. Then came Canadian Physicist Harriet Brooks who performed the pioneering experiments that led to the discovery of nuclear transmutation. Her experimental discovery that thorium gave out a radioactive gas with a smaller molecular weight than that of the original thorium was a critical key step in the history of nuclear physics (Woolbright et al., 2014).

Other scientists took the initiative of investigating other radioactive elements taking a cue from earlier experiments and discoveries as a buildup on previous discoveries or bring out new discoveries altogether. Following the experiments by Enrico Fermi, Lise Meitner, Otto Hahn and Fritz Strassmann, they focused their 
research efforts on the Uranium Problem. Lise Meitner in November 1938 met with Hahn in Copenhagen to discuss the experimental results in the group. Later, analyzing the results from the experiments together with her nephew, the physicist Otto Robert Frisch, she identified the new product of the reaction as barium and the nuclear fission was discovered. Otto Robert Frisch was the scientist who introduced the term 'fission' to describe the splitting of a heavy nucleus into smaller nuclei of about the same size (Woolbright et al., 2014). Otto Robert Frisch after his initial experiment and coining the term 'fusion' went further to carry out other experiments in this field of fission of radioactive. In 1939, he directly observed nuclear fission using an ionization chamber to detect the fragments from fission, an experiment that he managed to perform in only two days. Even before the nuclear fission reaction was observed, the Hungarian-born Jewish physicist Leo Szilard had postulated the possibility for controlled release of the energy of the atom via neutron chain reaction. He holds the first patent on the neutron chain reaction from the British Patent Agency, filed in 1934 and approved in 1936 (Woolbright et al., 2014).

Countries now absorbed these discoveries into their systems to harness their benefits, thus the first controlled fission of an atom occurred in 1938 in Germany. The U.S. was the first to develop an atomic bomb. In 1945, the U.S. military dropped bombs on the Japanese cities of Hiroshima and Nagasaki. During the fifty years following WWII, the major super powers conducted secret projects related to the building and testing of bombs. A legacy of the military research is that a great deal of soil, water and air are contaminated with radioactive material (Hanford, Savannah River sites). After WWII many people began to see the potential for using nuclear energy for peaceful purposes. The world's first electricity reactor was constructed in the U.S. in 1951. In December 1953, President Dwight D. Eisenhower, in his 'Atoms for Peace' speech said, "Nuclear reactors will produce electricity so cheaply that it will not be necessary to meter it, the user will pay an annual fee and use as much electricity as they want. Atoms will provide a safe, clean and dependable source of electricity. The Russians built their first plant in 1954 (Nuclear Energy, 2016). To produce electricity from nuclear energy, it is essential to have nuclear reactors which are the primary media through which electricity from nuclear power can be taped before connected to the grid for transmission to consumers and for other purposes. In view of that, countries which embraced nuclear energy invested in developing nuclear reactors to satisfy this quest. This saw the first nuclear reactors designed to produce plutonium for their respective nuclear weapons programs. "The development of atomic energy for peaceful purposes and the development of atomic energy for bombs are in much of their course interchangeable and interdependent." In the post war era, as Britain still had to import relatively expensive oil, policy makers thought that nuclear energy could be a cheap alternative. The shift from military to peaceful uses of nuclear power gained traction in 1953 when President Eisenhower proposed his "Atoms for Peace" program, suggested nuclear materials be used to provide "abundant electrical energy in the power-starved areas of the world." This was beneficial to governments who were keen to develop their nuclear weapons program away from the glare of public scrutiny (Walls and Harrison, 2011).

The concept of the atom has existed for many centuries. But we only recently began to understand the enormous power contained in the tiny mass. In the year just before and during World War II, nuclear research focused mainly on the development of defense weapons. Later, scientists concentrated on peaceful applications of nuclear technology. An important use of nuclear energy is the generation of electricity. After years of research, scientists have successfully applied nuclear technology to many other scientific, medical and industrial purposes (US Department of Energy, 2017). The 1950s saw the aims of countries venturing into nuclear research realized as it was resolved that electricity could be generated from nuclear energy for commercial use and not just atomic bombs. Shipping port, Pennsylvania was the location for the first commercial electricity- generating plant powered by nuclear energy and it reached its full design in 1957 (US Department of Energy, 2017). Thirty-one other countries by the end of 1991 were operating these commercial nuclear plants or were under construction, signifying advancement in world-wide commitment to nuclear power technology (US Department of Energy, 2017). In the early decades of the twentieth century, a revolution in physics came on stream, when in 1898 the French physicist Pierre Curie and his wife Maria Sklodowska-Curie discovered that present in pitchblende, an ore of uranium, was a substance named radium which was highly radioactive as it emits lots of radioactivity. It uplifted the spirits of scientists and laymen alike as many believed the elements around contained enormous amount of energy which has not been fully tapped (US Department of Energy, 2017). As scientists kept on advancing their research into radioactive elements, the man credited as the father of nuclear physics Ernest Rutherford is also noted for splitting the 
atom with naturally occurring alpha particles from radioactive material and also observed a proton emitted with energy higher than the alpha particle. This split was carried out by his team in England by bombarding nitrogen with the naturally occurring alpha particles. Two other scientists who carried out splitting were Rutherford's students, John Cockcroft and Ernest Walton, working under the tutelage of Ernest Rutherford. They attempted splitting by artificial means by using a particle accelerator to bombard lithium with protons, thereby producing two helium nuclei (US Department of Energy, 2017).

Another groundbreaking discovery was made when James Chadwick discovered the neutron in 1932. This spurred Enrico Fermi on to be the first to achieve nuclear fission experimentally in Rome in 1934, as his team also bombarded uranium with neutrons. Some scientists experimented with neutron-bombarded uranium. In 1938, German chemists Otto Hahn and Fritz Strassmann along with Austrian physicists Lise Meitner and Otto Robert Frisch took on this initiative. Scientists like Leo Szilard was one of the first to recognize that if fission reactions released additional neutrons, a self-sustaining nuclear chain reactor could result (US Department of Energy, 2017). On $20^{\text {th }}$ December, 1951, the EBR-1 experimental station near Arco, Idaho became significant for the generation of electricity. The plant initially produced about $100 \mathrm{~kW}$ (the Arco Reactor was also the first to experience partial meltdown, in 1955). The Paley Commission report for President Harry Truman in 1952 made a 'relatively pessimistic' assessment of nuclear power, and called for 'aggressive research in the whole field of solar energy.' President Dwight Eisenhower's 'Atoms for Peace' speech emphasized the useful harnessing of the atom and set the U.S. on a course of strong government support for international use of nuclear power. The breeder served to harness useful energy which can be extracted from natural uranium, such that the Atomic Energy Commission of the U.S. announced on June 4, 1953 that the EBR-1 had become the world's first reactor to demonstrate the breeding of plutonium from uranium (US Department of Energy, 2017).

Following the history of nuclear energy is its importance or significance. According to de De Groot et al. (2010), it has been argued that an increase in the use of nuclear energy may help to safeguard security of energy supplies and contribute to climate change mitigation through reduced $\mathrm{CO}_{2}$ emissions (de Groot, Steg and Poortinga, 2013). According to Amanda Beckrich, nuclear energy is fit, it is safe, and it is back: nuclear power is a viable energy option again. So asserts the nuclear industry, key politicians and other stakeholders who see a nuclear renaissance ahead. It is fit because it is the only major source of electricity that does not produce greenhouse gases. It is safe because of nearly two decades of accident-free operations and because of a new generation of 'inherently safe' reactors (Beckrich, 2013). Bruno Comby believes that nuclear energy is a clean, safe, reliable and competitive energy source. It is the only source of energy that can replace a significant part of the fossil fuels (coal, oil and gas) which massively pollute the atmosphere and contribute to the greenhouse effect. Tomorrow's nuclear electric power plants will also provide power for electric vehicles for cleaner transportation. With the new high temperature reactors, we will be able to recover fresh water from the sea and support hydrogen production (Comby, 2006). He emphasizes that nuclear power is clean, safe, reliable, compact, competitively and practically inexhaustible. Today, over four hundred nuclear reactors provide base-load electric power in thirty countries. Fifty years old, it is a relatively mature technology with the assurance of great improvement in the next generation. Nuclear energy produces almost no carbon dioxide, and no sulfur dioxide or nitrogen oxide whatsoever. These gases are produced in vast quantities when fossil fuels are burned (Comby, 2006). Compared to fossil fuel, nuclear power's safety has been proven by half of a century's record with an accumulated experience of 12,000 reactor-years. The base-load of these nuclear reactors can be relied upon $90 \%$ of the time as intervals between refueling have been extended and down time for refueling has been reduced. Again, the cost of running or operating a nuclear plant is relatively stable and cost efficient. The cost of nuclear fuel is a small part of the price of a nuclear kilowatt-hour, whereas fossil fueled power, especially oil and gas, is at the mercy of the market (Comby, 2006).

Comparing nuclear energy to natural gas has shown that one kilogram of uranium can illuminate fourteen 100 -watt light bulbs for ten years. With the same amount, natural gas and coal can light equal number of bulbs for only ten and six hours respectively. This makes electricity production from nuclear energy cheap, powerful, reliable and efficient. It is also proven that nuclear energy does not generate or release greenhouse gases, which are the main causes of global warming and ozone layer depletion, making it environmentally clean. Again, nuclear waste has lots of guidelines on how to effectively manage them (Klutse, 2016). International climate experts are considering the full application of nuclear energy in the protection of the 
environment by keeping the temperature under $2^{\circ} \mathrm{C}$ increase by 2050. In examining the facts, it has been realized that $0.0035 \mathrm{GW} / \mathrm{hr}$ of power to power an average household annually and to obtain this threshold, 7 Grams of uranium (nuclear fuel), which is equivalent to the release of $56 \mathrm{~kg} \mathrm{CO}_{2} /$ year. That also translates into $890 \mathrm{~kg}$ of oil, also equivalent to $2,620 \mathrm{~kg} \mathrm{CO} /$ year, $1,100 \mathrm{~kg}$ of coal, equivalent to $3,503 \mathrm{~kg} \mathrm{CO}_{2} /$ year and $1,000 \mathrm{~m}^{3}$ of gas, equivalent to $1,736 \mathrm{~kg} \mathrm{CO}_{2} /$ year. Nuclear energy is believed to emit less carbon dioxide over these sources of power and is environmentally friendly (Gawusu, 2016). Students from the School of Nuclear and Allied Sciences (SNAS) of the University of Ghana, Legon and the STEM fields will be beneficiaries of jobs which will be created by clean energy aside reducing emissions (Gawusu, 2016). As it has been proven with nuclear energy so is wind and solar power environmentally as they are a low carbon energy source that emit only 16 grams of $\mathrm{CO}_{2} / \mathrm{kWh}$. The waste produced from nuclear is effectively monitored since a number of regulations exist on how nuclear waste is to be managed. As a very competitive source of electricity, power is generated for all hours of the day and night. Nuclear energy is serving the purpose of providing a lasting solution to the climatic and electricity shortcomings of countries of the world, as it provides stable and steady power and ensures electric grid reliability (Gawusu, 2016).

The atomic nuclei is a very important source of energy, which is gained from disintegrating atomic nuclei and has the potential to improve the lives of people globally. Statistics have revealed that about $17 \%$ of the energy in the world is gained from nuclear power plants. These radioactive isotopes are instrumental in the field of nuclear medicine, where X-rays are used to examine fractures and scan for any malfunctions inside the human body; also diagnosis and the treatment of cancer are all done with the help of radioactivity (Nuclear Energy, 2016). Nuclear power is credited as a mature and well-established technology, since it emits less carbon dioxide and is widely believed to play a vital role in the curbing the issue of global warming. Unlike electricity generated from coal or natural gas, nuclear power is relatively clean, producing almost no emissions. It is a very reliable source of power as opposed to wind and solar in spite of their generation qualities as well. The cost of building and running nuclear plants is huge; however, they are the most effective as compared to other low-greenhouse-gas electric-generation mechanisms (Feiveson, 2009). According to Feiveson, "when the total bus-bar costs are considered, nuclear appears at least arguably competitive with integrated gasification combined cycle coal (IGCC) and combined cycle gas turbine (CCGT) plants, if there is a carbon charge roughly in the range of $\$ 30$ to $\$ 50$ per ton of $\mathrm{CO}_{2}$ emitted (Feiveson, 2009). In some regions where wind energy is the major source of electricity generation, nuclear energy supplements it to ensure a continuous supply of power (Feiveson, 2009). Nuclear power is the result of man's quest to explore the positive use of radioactive elements for use by humans. For this reason, it portrays the sterling achievements made over the years to bring to the fore the benefits of harnessing nuclear power from the smallest of particles. Now $1 \mathrm{~kg}$ of uranium $\mathrm{U}^{238}$ is capable of producing as much energy as will $35,000 \mathrm{~kg}$ of coal (Bose, 1981). Although nuclear energy like any other source of electricity generation is bereft with shortcomings, its merits overrides that of the others. Nuclear energy provides a safe haven for man as he determines the next course of action at finding a more effective source of power to satisfy his needs. Nuclear energy is able to generate more power with little uranium fuel and also safeguards the earth's ozone layer from carbon emissions. As coal for instance, involves a sophisticated structure required for processing fuel needed to power coal plants, nuclear requires a relatively cost effective source of power (Bose, 1981). Nuclear energy is capable of supplementing the existing forms of power generation as a peaceful application of it rather than manufacture of atomic bombs (Nickson and Brown, 1947).

According to Nickson and Harrison (1947), another application of nuclear energy is for solving industrial problems. One obvious application will be in the control of a wide variety of plant processes. It seems feasible to predict that many complicated and costly present-day inspection systems will rely upon the use of the byproducts of nuclear energy. One of the most important immediate applications of nuclear energy and its byproducts will be the solution of problems in biology and medicine (Nickson and Brown, 1947). Nuclear energy has the potential of saving the volume of oil burnt by coal-powered-plants daily. A 1,000 mw nuclear plant can save up to 30,000 barrels of residual oil burnt daily by an oil-burning plant and it can also save up to 20,000 barrels if its output were used for resistive heating per heating day. Furthermore, it can be used for energizing heat pumps of perhaps 40,000 barrels per heating day (Weinberg, 1980). Although there are some skeptics and opposition to the full realization of nuclear power in some countries, there are many more who believe in the prospects of nuclear energy to arrest the issue of high rising carbon emissions and greenhouse effect. A recent article in Wired magazine put it as, "some of the world's most thoughtful greens have 
discovered the logic of nuclear power"- suggesting that "a clean green future" is very possible if we "start building nuke plants and keep building them at a furious pace" (Center for the Study of Technology and Society, 2016). A coal plant can emit about six million tons of carbon dioxide and sixteen thousand tons of nitrous oxide and a natural gas plant emits one hundred and forty million tons of carbon dioxide. This is not true for nuclear power which is highly considered due to its zero emissions of carbon dioxide, Sulphur dioxide or nitrous oxide. According to the World Nuclear Association (WNA), "if the entire world's nuclear power were replaced by coal-fired power, electricity's carbon dioxide emissions would rise by a third" (Bratt, 2005).

According to the Canadian Nuclear Association, "the use of nuclear power at Qinshan will reduce the quantity of carbon dioxide produced in China by nine million tonnes per year compared with coal, which would have been used if nuclear power was not available. From the project commissioning in 2003 to the end of 2012, this project will avoid, in total, over eighty-five million tonnes of carbon dioxide" (Bratt, 2005). It is advisable for economies of countries to adopt nuclear energy as an option in the production and distribution of electricity because it saves fuel which will otherwise be used by coal and natural gas plants. However, uranium fuel which is used by nuclear plants can be re-used for up to ten years before totally discarding it (Birikorang et al., 2012). Nuclear is a better option for countries with little or no fossil fuel reserves but desire to ensure the continuous generation of power to feed its industries and the nation at large; countries in this category include South Korea, Japan, France, and so on who can rely on nuclear power in the absence of fossil fuel. Again, the lifetime of the new breeds of nuclear plants could last up to sixty years. There currently are steps to increase this further. As stated earlier, though the cost of building nuclear plants is huge, the fuel for running them are cheaper and can be reused for a period of time before disposing them off. These plants are a sure protection from the fluctuating prices of oil on the global market; uranium fuel's cost is stable. The new nuclear plants coming on stream are cost efficient (Birikorang et al., 2012).

According to Birikorang et al. (2012) given its low emissions, nuclear power is seen by many as part of the solution to meet, for example, the new environmental constraints, like entry-into-force of the Kyoto protocol, and the 2007 G8 summit goal of cutting global emissions in half by 2050. Nuclear power is a mature technology with more than half a century of operating experience. The past two decades have seen significant improvements in nuclear power plant reliability, as well as lower operating costs, and a progressively improved safety record (Birikorang et al., 2012). Nuclear energy is an essential drive at ensuring food security. This is because the process of irradiation kills bacteria and parasites present in food, including listeria, salmonella and potentially deadly E. Coli and is very instrumental at preventing non-microbial spoilage of certain foods, thereby increasing their shelf life (Napavalley, 2011). Radiation is also useful in the areas of cosmetics as radiation is used to sterilize baby powder, bandages, contact lens solution and several other cosmetics, including false eyelashes and mascara (Napavalley, 2011). Radioactivity is used as tracers in process materials to track leakage from piping systems, monitor the extent of wear in an engine and corrosion of processing equipment, and to also examine the velocity of materials through pipes and gauge system filtration efficiency (Napavalley, 2011). The automobile industry is a testament to the usefulness of nuclear energy as radioactive materials are used to test the quality of the steel of cars. Also in the aviation industry, manufacturers use radiation to check for faults in jet engines. There is also the question of whether manufacturers can use radioactive materials to obtain the proper thickness of tin and aluminum (Napavalley, 2011).

\section{Ghana's Quest for Nuclear Energy}

This section pays attention at Ghana's efforts to build a nuclear plant. It discusses the reasons for a nuclear plant, the preparedness of existing institutions to take up the challenge among others.

Why was Ghana Planning and Continues to Plan for a Nuclear Program? Ghana continues to face serious power crisis with its attendant strain on the economy and a crush on general industrial output. This crisis is one of the most severe energy shortfalls ever to hit the country since the 1980s. Since this crisis began, several considerations have been brought forth to forestall future energy needs. These include investing in other energy sources apart from the traditional hydro-electricity; nuclear energy appears to be the most promising of the rest (Klutse, 2016). The Convention People's Party (CPP) Government of the first Republic 
set out with an industrial drive to revolutionize the country's economy. This led to the construction of the Akosombo hydro-electric dam. Other areas identified as likely considerations for a similar project were Bui, the Tano and Ankobra for complementing the existing dam and further augmenting the country's energy capacity. In addition, the Nkrumah Government began planning for nuclear energy by procuring a reactor for the country under the Ghana Atomic Energy Project to cater for the needs of the country's emerging industries (Dadzie, 2016). Dr. Kwame Nkrumah when inaugurating the Ghana Atomic Energy Project on November 25, 1964, made the following remarks: "we have therefore been compelled to enter the field of Atomic energy, because this already promises to yield the most economic source of power since the beginning of man. Our sources in this field would enable us to solve the many sided problems which face us in all the spheres of our development in Ghana and in Africa (Dadzie, 2016).

It can be inferred that Dr. Kwame Nkrumah was set on making nuclear energy an integral part of the nation's energy mix. Experiments involving the use of radio-isotopes had begun at the University of Ghana (Legon) in the early 1950s, which exposed the great potentials the nation stands to gain if it adopted nuclear power. The Defense Ministry in 1958 carried out a nuclear fallout monitoring service on behalf of the University of Ghana due to fears of public hazards from radioactive fallout from nuclear weapon tests (Amuzu, 2016). The Kwabenya Nuclear Reactor Project was initiated by the government in 1961, "to introduce nuclear science and technology into the country and to exploit nuclear energy in its peaceful applications [for] the solution of problems of national development (Amuzu, 2016). It was anticipated that the government could augment the generating capacity at 500MW by 2015 to make her energy sufficient and also an exporter of power in the West African sub-region. The country experienced load shedding in 2014 which was carried out by the Electricity Company of Ghana. Demands by 2015 were pegged at 19.5 billion $\mathrm{kw} / \mathrm{h}$. The government announced plans to re-visit nuclear energy to safeguard Ghana's energy sources and in 2008 estimated 400 mw of nuclear power by 2018 (World Nuclear Association, 2016).

According to Nyarko et al. (2009) Ghana's Growth and Reduction Strategy (GGRS) is focused on the transformation of the Ghanaian economy from its current low or middle income status to a middle income with a per capita of about $\$ 1,000$ by 2015 . This however, would require cost competitive, environmentally friendly and reliable source of grid electricity. Should the GGRS target be realized, demand for energy is expected to rise steadily. In the midst of these uncertainties, nuclear power could provide at least $10 \%$ of the installed capacity by 2020 (Nyarko, Akaho and Ennison, 2009). The 1961 Kwabenya Nuclear Reactor Project (KNPP) pursued by the first Republican government was aimed at introducing nuclear science and technology into Ghana, to provide a suitable nuclear infrastructure for the incoming nuclear programme the country has opted for and to eventually acquire maximum electric power for the country's industries (Nyarko, Akaho and Ennison, 2009). In 2007, the Nuclear Power Project was revisited due to a severe drought in the sub-region between 2003 and 2006 which led to a drop of 44\% in water inflow into the Volta Lake in 2006 (Nyarko, Akaho and Ennison, 2009). The President of Ghana in 2008 established a committee which became the Nuclear Power Planning Committee (NPPC) to involve Stakeholder Institutions. This committee was tasked to formulate a feasible Nuclear Power Policy and help develop basic elements for the nuclear infrastructure (Nyarko, Akaho and Ennison, 2009). The concern of the Government of Ghana was with high cost of imported oil and gas and other environmental issues due to global warming as well as the demerits associated with hydro-electricity as it heavily relies on weather. This led to the formation of a Committee to supervise Ghana's nuclear programme. Though there are provisions for wind and solar plants, developing them on a large-scale is currently not envisaged for the future (Nyarko, Akaho and Ennison, 2009).

Ghana experienced its worst power crisis in 2007 due to inadequate funds to procure light crude to power thermal plants. Some of these plants were obsolete and required replacement. Again, the West African Gas pipeline could not supply enough gas for the country's plants which run on the product. All these culminated in a cabinet decision to build a 400 MW nuclear power plant by 2018 from the Committee's report set up by the President of Ghana on the viability for this new venture (Birikorang et al., 2012). The country has decided to adopt nuclear energy like several others for various reasons. Ghana's drive for sustainable development requires a constant and reliable source of electricity and nuclear energy is one sure way to make this vision a success. The demands or load on the country's energy resources are over-stretched and this has necessitated a proposition for nuclear to be added to the country's energy mix. It has been estimated that by the year 2020 Ghana's energy demands will rise from 1200MW T0 3630MW (Birikorang et al., 2012). One merit of nuclear 
plants is the price stability of the nuclear fuel and the ability of it being re-used before completely discarding it. This is because nuclear plants require low fuel supply and the fuel can be stocked for up to ten years by reducing the risks associated with fuel shortage and price fluctuations. Nuclear fuel is easily acquired since there are several establishments which specialize in that sector. Also, nuclear fuels only power nuclear plants (Birikorang et al., 2012). The motive for the project was to help Ghana develop a long-term energy plan by determining future energy and electricity demand as well as the future energy sources or resources essential for Ghana's energy mix for a sustainable plan for the energy sector (Boussaha et al., 2007).

Are The Institutions Well-Prepared For This Task? This aspect of the paper highlights the preparedness or otherwise of the sole institution, the Ghana Atomic Energy Commission, which has been tasked to ensure Ghana's nuclear programme comes to fruition. It also analyzes the agencies under the Commission and how they are helping with the programme. One of the thoughts which floods the minds of Ghanaians particularly is how well our institutions are prepared for the tasks assigned to them and most importantly an Atomic Agency's capabilities lie in its efficiency at managing radioactive waste which if not tackled tactfully can prove dangerous to the health of the people and the environment in general. These fears ought to be discarded since Ghana already has a long history of managing radioactive waste from medical equipment as well as industrial ones, thus fears of radioactive waste management need not be a problem. Again, the International Atomic Energy Commission (IAEA) has regulations for the management of radioactive waste (Klutse, 2016). Work on Ghana's nuclear programme is at an advanced stage as the infrastructure is ongoing with the needed human resource required to manage it under regular training to ensure they are well-prepared for the job at hand. An appropriate site for the construction of the plant has been sourced with its attendant feasibility studies and stakeholder consultation. The IAEA has already cleared the country to go ahead with the programme (Bannor, 2014). As part of plans to formulate the best policy guidelines for a swift execution of the nuclear power project, an independent Nuclear Regulatory Authority is on course for action as a bill is before the National Legislature awaiting passage. This authority will supervise the activities of the GAEC in every process involving the programme. This has not been possible without the support of the Government (Bannor, 2014).

With the help of the IAEA through its technical support programme for countries entering into the nuclear industry, Ghana will soon take delivery of its first nuclear plant to help its numerous initiatives aimed at improving the socio-economic outlook of the country. It will also be the first of its kind in the West-African sub-region (Bannor, 2014). As part of the country's aim at developing the capabilities of its human resource for the project, the Graduate School of Nuclear and Allied Sciences (SNAS) at the University of Ghana has been instituted to pursue this course to aid in the Nuclear Knowledge Management (NKM) programme. The school is an IAEA African Regional Designated Centre (RDC) for Professional Training and Higher Education in Nuclear Science and Technology and Radiation Protection (Bannor, 2014). With the support of the IAEA, Ghana has developed a set of draft Radioactive Waste Management regulations and a Radioactive Waste Management Policy and Strategy in addition to equipping its human resource to ensure they are up to date on these policies and strategies (Bannor, 2014).

According to Dr. Albert W. N. Q. Bannor, since 1978, various national and international activities have been undertaken by Member States, with the support of the Agency, to convert Highly Enriched Uranium fuel (HEU)-based research and test reactors (RRs) to Low Enriched Uranium (LEU) fuel. Ghana has in that regard conducted feasibility studies for the possible conversion of her research reactor from HEU to LEU with the support of the IAEA and the Argonne National Laboratory (ANL). A reactor Core Conversion Safety Analysis Report (CC SAR) has since been completed. In line with the international efforts, plans to return HEU spent fuel were initiated in February 2011, when an international MNSR Working Group (WG) was established to coordinate these activities. Ghana has officially requested the Agency's assistance in the removal and transportation of the irradiated HEU MNSR core. A Project and Supply Agreement (PSA) has also been assigned by Ghana and China, with the Agency's support and guidance to ship the first LEU fuel to Ghana ((Bannor, 2014). Ghana has always approved and supported nuclear security programs carried out by the IAEA. Thus the country is very much aware of the concerns raised by member states on their responsibility to ensure nuclear security in their respective nations and the world as a whole (Bannor, 2014). To develop the human resource base needed for the take-off of the country's nuclear programme, the Ghana Atomic Energy Commission (GAEC) in collaboration with the University of Ghana with support from the International Atomic 
Energy Agency (IAEA) has established the Graduate School of Nuclear Allied Sciences which runs a postgraduate programme in different areas associated with nuclear energy. The country still partakes in research by the IAEA to help increase the nation's knowledge of nuclear science and technology. GAEC also keeps contact with other International Agencies such as Global Nuclear Energy Partnership (GNEP) all geared towards realization of the vision (Nyarko et al., 2009). Ghana has well-endowed nuclear scientists with the ability to manage any advanced level technology in the field without any setbacks. The Ghana Atomic Energy Commission since 1995 has been operating a 30-kilowatt research reactor (GHARR-1) at Kwabenya. Interestingly, only well trained Ghanaian personnel are in charge of this nuclear research reactor and its safety record has been praised by the IAEA as satisfactory. The country has also signed the Non-Proliferation Act (NPA) and other Safeguard Protocols to deter the country from using its nuclear resources for war purposes (Nyarko et al., 2009).

According to Nyarko et al. (2009) human resource capacity building currently in place is in two forms, that is, degree and non-degree awarding programs. In the degree awarding category, Ghana Atomic Energy Commission (GAEC) has established the Graduate School of Nuclear and Allied Sciences in collaboration with the University of Ghana with assistance from the International Atomic Energy Agency (IAEA) to award masters and Ph.D. degrees in nuclear science. The school currently has five departments offering ten accredited programs. Programs in place which are directly related to the nuclear power programs includes; Nuclear Engineering, Applied Nuclear Physics, Nuclear and Environmental Protection, Nuclear and Radiochemistry, Nuclear Security and Safety and Radiation Protection (Nyarko et al., 2009). There are some non-degree programs run at the Graduate School of Nuclear Allied Sciences which involves training and teaching nuclear scientists and technicians on the use of the 30-kilowatt research reactor in areas like reactor operation, physics, safety, engineering, maintenance and so on. The IAEA also has Technical Cooperation Projects (TCs) like GHA0008; Planning for sustainable energy development, GHA009; Human resource development and nuclear support technology support, GHA0011; Evaluating the role of nuclear power in future options for electricity generation and coordinated research projects such as Core Conversion and Benchmarking for safety, and many more. All these have gone a long way to improve the country's knowledge base on the subject matter. Ghana still makes appearances at IAEA training courses and workshops on national, regional and international levels. GAEC continuously maintains correspondence with other International Nuclear Agencies such as Global Nuclear Energy Partnership (GNEP) (Nyarko et al., 2009).

Ghana Atomic Energy Commission: This section focuses on the Ghana Atomic Energy Commission which is the institution charged with the responsibility of regulating, supervising, administering and overseeing Ghana's nuclear program and also maps out the modalities in place to ensure how Ghana manages its nuclear resources effectively and benefits from these resources. In addition, the structure or nature of nuclear energy will also be looked at. This will involve the various nuclear plants and its constituents and the advantages and disadvantages of a type of nuclear plant. Again, GAEC's agencies and their functions will also be examined.

The Nuclear Plant, How It Works and Its Components: Serving as the primary channel through which electricity is generated from nuclear sources is the nuclear plant. Like every other plant for electricity generation, it has its own type of fuel that powers it and how it is operated and what constitutes any nuclear plant whatever the type or model. Nuclear power is power generated from controlled nuclear reactions. Nuclear plants today are mostly fit for fission reactions. The electric utility reactors heat water to produce steam, which is then used to generate electricity. More than 100 nuclear power plants today provide $20 \%$ of the electricity consumed in the United States. Again, there are over 439 reactors providing some $17 \%$ of the world's electricity needs, and about 65 of these plants are under construction globally. 2009 saw $15 \%$ of the world's electricity from nuclear resources, in spite of the concerns raised about safety and radioactive waste management. Naval vessels numbering more than 150 have been built, which operates on nuclear propulsion (Ledoshchuk, 2016). The nuclear plant is often referred to as nuclear reactor because a nuclear plant is centered round the reactor. The reactor is housed in the containment building with the core of the reactor being the heart of the plant. Like the fossil-fuel generators, the reactor generates the heat that boils the water into steam. This steam turns the turbine in the turbine building to produce the needed electricity. Finally, the water flows from the cooling water source to help re-condense the steam into water before it flows back into the reactor building to be boiled into steam again (Klutse, 2016). There are several types of nuclear reactor configuration. These include high-temperature gas-cooled reactor, boiling water reactor and pressurized 
water reactor. Common to these reactor configurations is the reactor core, which contains the fuel assembly. The fuel assembly is a complex set-up that ensures and maintains a controlled nuclear fission. The major components of the plant are uranium fuel and the control rods. Uranium starts out as ore just like gold ore, and contains a very low percentage (or low enrichment) of the desired atoms (U-235). The U-235 is a more desirable atom for fuel because it undergoes fission early. Uranium is a fissionable material. U-238 atoms are however, much more abundant. The fuel fabrication process, therefore, includes steps to increase the number of U-235 atoms in relation to the number of U-238 atoms (enrichment process). It is this enriched uranium which is loaded into the reactor core. Though it is based on a lower technology, the enrichment process for nuclear power reactor could produce an atomic bomb. That is what raises the controversy with a country's development or acquisition of nuclear enrichment technology (Klutse, 2016).

To go round this, reactor grade enriched uranium are always available commercially. To produce the heat needed for steam generation, uranium undergoes a lot of changes whose description is beyond the scope of this discussion. The change process is referred to as fission. An atom is made up of a cloud of electrons surrounding a tiny but highly dense nucleus. The whole of matter is therefore concentrated in the nucleus. In the reactor, the nucleus of a uranium atom undergoes splitting (fusioning) to form daughter nuclei leading to the release of a huge amount of energy in the form of heat. The boiling water reactor operation is a typical example of the operation of a fossil-fuelled generating plant. Inside the reactor vessel, a steam or water mixture is produced when pure water (reactor coolant) moves upward through the core absorbing heat. The steam or water mixture leaves the top of the core and enters two stages of moisture separation, where water droplets are removed before the steam is allowed to enter the steam line. The steam line, in turn, directs the steam to the main turbine, causing it to turn the turbine and the attached electrical generator. The unused steam is exhausted to the condenser where it is condensed into water. The resulting water (condensate) is pumped out of the condenser with a series of pumps and back to the reactor vessel. The recirculation pumps and the jet pumps allow the operator to vary coolant flow through the core, and to change reactor power (Klutse, 2016).

To operate properly, all steam plants, whether nuclear or fossil-fuelled need a circulating water system to remove excess heat from the steam system in order to condense the steam, and transfer that heat to the environment. The circulating water system pumps water from the environment (river, lake or ocean) through thousands of metal tubes in the plant's condenser. Steam exiting the plant's turbine is very rapidly cooled and condensed into water when it comes in contact with the much cooler tubes (Klutse, 2016). Since the tubes provide a barrier between the steam and the environment, there is no physical contact between the plant's steam and the cooling water. Because a condenser operates at a vacuum, any tube leakage in this system will produce an "inflow" of water into the condenser rather than an "outflow" of water to the environment (Klutse, 2016). Commercial nuclear power plants in the United States are either boiling water reactors (BWRs) or pressurized water reactors (PWRs). Both are cooled by regular water. BWRs heat water surrounding the nuclear fuel directly into steam in the reactor vessel. Pipes carry steam to the turbine, which drives the electric generator to produce electricity. PWRs heat the water surrounding the nuclear fuel, but keep the water under pressure to prevent boiling. The hot water is pumped from the reactor vessel to a steam generator. There, the heat from the water is transferred to a second, separate supply of water. This water boils to make steam. The steam spins the turbine, which drives the electric generator to produce electricity. About two-thirds of the nuclear reactors in the United States are PWRs, and one-third are BWRs (Palliser, 2012).

The Ghana Atomic Energy Commission: The beginning of what is now Ghana Atomic Energy Commission (GAEC) could be traced far back as 1952 when the use of radioisotopes began in Ghana. At that time, radio strontium was used in experiments on monkeys. In 1958, the Physics Department of the University College of the Gold Coast (now University of Ghana, Legon) on behalf of the Ministry of Defense started radioactive fallout monitoring service. By the end of 1959, work in radioisotope applications in Ghana had sufficiently gained ground in a number of institutions to justify the establishment of a Radioisotope Unit (GAEC, 2016). In 1961, the Government of Ghana decided to undertake the "Ghana Nuclear Reactor Project (GNRP)." This was intended to introduce nuclear science and technology into the country and to exploit the peaceful applications of nuclear energy to foster national development. The central facility of the project was to be a research reactor designed solely for research, training and production of radioisotopes. The long term 
strategic objective of this initiative was that the research would facilitate the development of manpower and promote plans for the introduction of nuclear power for electricity generation in the country. To help realize the objective of the Ghana Nuclear Reactor Project, the Ghana Atomic Energy Commission was founded by an Act of Parliament (GAEC, 2016).

The Vision or Plan for the Project: In 1960 the President of the First Republic, Osagyefo Dr. Kwame Nkrumah made a political decision for Ghana to pursue a Nuclear Reactor Programme. He conceived the idea of meeting Ghana's electricity needs with two major projects- the Akosombo Hydroelectric Dam and a Nuclear Power Reactor. At the ceremony marking the laying of foundation stone for the Atomic Complex on 25th November, 1964, Dr. Nkrumah said: Our sole motive in reaching the decision to build the Centre which you now see rising before you, is to enable Ghana to take advantage of the decisive methods of research and development which mark our modern world. It is essential to do this if we are to impart to our development that acceleration which is required to break even with more advanced economies. We have therefore been compelled to enter the field of atomic energy, because this already promises to yield the greatest economic source of power since the beginning of man (GAEC, 2016). This was the era of Russian sputniks that dominated the outer space. It was also a time when nuclear science as a study had some global appeal, and nuclear power reactors were considered as an inevitable option that many countries were likely to adopt to solve their energy problems (GAEC, 2016).

In Ghana at that time the word 'atomic' was conceived by the general public as having "magical" possibilities. These and perhaps other factors might have shaped Dr. Nkrumah's vision on nuclear reactors (both research and power) for Ghana. He was indeed an outstanding visionary. In 1960, the Government therefore decided to set up the Reactor Programme under a Credit Agreement previously concluded with the Government of the U.S.S.R. A delegation sent to the U.S.S.R. to negotiate for both a Research Reactor and a Power Reactor, on its return, recommended the procurement of a Research Reactor only to begin with (GAEC, 2016). On September, 1960, Ghana applied and became a member of the International Atomic Energy Agency (IAEA) the third country from black Africa to be admitted as a member of the Agency. In 1961, a Protocol Agreement was signed and ratified by the Government of Ghana and the U.S.S.R. for the building of a 2 MW Swimming Pool Soviet-made (Type IRT 2000) Research Reactor with the possibility for upgrading to 5 MW under the Ghana Atomic Energy Reactor Project. Following feasibility studies, based on topography, groundwater status and density of human settlement, etc. carried out by Ghanaian specialists in collaboration with Soviet experts, the present site near Dome village about two miles from Kwabenya village was acquired for the project (GAEC, 2016).

The Ghana Atomic Energy Committee: Responsibility for the implementation of the Nuclear Reactor Project was vested in the Ghana Atomic Energy Committee which was set up in 1961. The Fuel and Power Secretariat at the Flagstaff House exercised governmental oversight over the Reactor Project. But the Project was placed under the Ghana Academy of Science for technical direction. Dr. R.P. Baffour, the then ViceChairman of the Academy of Science and Dr. J.Y. Ewusie, the then General Secretary of the Academy became the Chairman and Secretary respectively of the Ghana Atomic Energy Committee. They both formulated the Executive Instrument for the Project (GAEC, 2016).

The Establishment of the Ghana Atomic Energy Commission: To consolidate Dr. Nkrumah's vision, the Nuclear Reactor Project was created by an Act of Parliament, Act 204, in 1963 which, among other things, established the Ghana Atomic Energy Commission (GAEC) to replace the Ghana Atomic Energy Committee and to be in charge of the Project. The membership of the Commission at the time of its inauguration consisted of the people: Dr. R.P. Baffour as Chairman, Dr. D.A. Bekoe, Prof. F.K. Kufuor as Members, Prof. J.E.O. Lindsay as ex-officio member and Dr. J.Y. Ewusie as Secretary and a member as well. This Act vested in the Commission responsibility in Ghana for all matters relating to the peaceful uses of atomic energy. At the same time, it conferred on the Commission the following powers and functions: one is to maintain relations with the International Atomic Energy Agency and other similar International bodies, to make arrangements with other African countries and with the universities or other institutions of such countries for the conduct of research into matters connected with the peaceful uses of atomic energy, to make proposals to the Government for legislation in the field of atomic energy, to advise the Government on questions relating to atomic energy, to promote scientific and technical education in matters connected with the peaceful uses of 
atomic energy and to promote the establishment of the necessary installations for such education, to prospect for and use radioactive minerals and to produce, distribute and develop the uses of radioisotopes and finally to supervise generally the carrying out of all requirements designed to secure the safety and health of persons employed in work in the course of which they may be exposed to the risk of injury from ionizing radiations (GAEC, 2016). The central facility around which the nuclear energy research programme was to revolve was the Research Reactor designed for research, training and production of radioisotopes. The Kwame Nkrumah Nuclear Research Institute (KNNRI), also established in 1963 by the same Act 204, and the only research institute operating under the GAEC, was placed under the directorship of Professor J.E.O. Lindsay. Thus, the GAEC was established and placed under the Office of the President to realize all of the above objectives (GAEC, 2016).

Training of Staff: One of the initial tasks tackled by the Ghana Atomic Energy Committee, which was later replaced by the Ghana Atomic Energy Commission, was a programme of staff training and development for selected Ghanaians. In 1962, while various construction works were on-going, Mr. Hayford, the Principal Secretary under the Office of the President, recruited staff (Ghanaian physicists, chemists, mathematicians, engineers and technicians) for training in Moscow under a protocol agreement signed between the GAEC and the USSR State Committee for the peaceful uses of Atomic Energy. The first batch left for Moscow in September 1962. The training covered reactor physics and engineering, reactor operation, instrumentation and control, nuclear physics, radiobiology, radiochemistry and the production, processing and certification of radioisotopes and labeled compounds. Three months were initially spent in studying the Russian language at the Moscow Power Institute before the recruits undertook their respective training leading to Diplomas based on their fields of study (GAEC, 2016). In September 1963, a second year batch of trainees also went to Moscow and was again divided into two groups and given the same training that the earlier group had been given. On 14th April, 1964, all the trainees returned to Ghana. Since the Reactor Project was far from being completed, most of the scientists left for further training under the International Atomic Energy Agency fellowships in the U.K. and other European countries to pursue postgraduate studies for higher degrees. Some returned to the Commission after training, while others went to the universities in Ghana (GAEC, 2016).

Purpose of the Project: The Reactor Project was intended to introduce nuclear science and technology into the country and to exploit nuclear energy in its peaceful applications to the solution of problems of national development. In particular, the IRT 2000 Reactor was intended for the production of radioisotopes for use in the Health, Agricultural and Industrial Sectors of our economy. From a long-term point of view, it was hoped that the research reactor facility would provide the means for preparation for the development of manpower and promote plans for the introduction of nuclear power for electricity generation in the country (GAEC, 2016). After the February 1966 coup, the Nuclear Reactor Programme, the GAEC with all the plans and projects outlined for Ghana's switch to nuclear science and technology took a nose dive as the entire programme was placed on hold amidst several commissions of enquiries to ascertain the viability of the programme. This caused a lot of delays in executing the project. However, under the NDC Administration in 1993 saw a reformed and revived Ghana Atomic Energy Commission (GAEC). This saw the establishment of new institutes or centers under the Commission. This was in furtherance of the Atomic Energy Commission (Amendment) Law, PNDC 308 of 1993, which empowered the Commission to establish Institutes and Centers. As a result, the following Institutes and Centers were established (GAEC, 2016).

Institutes and Centers Under the Commission-The Radiation Protection Board: As part of structural reforms of the GAEC under the National Democratic Congress Government of 1993, some institutes and centers were established, one of which is the Radiation Protection Board. This Board was established by a Legislative Instrument, LI 1559, which was promulgated in January, 1993. It was governed by a Board consisting of a Chairman and eight other members, and empowered by the provisions of LI 1559 to carry out the following activities: to register and authorize practices which involve the use of radiation and radioactive materials and sources, conduct inspections for the purposes of issuance of authorization as well as regular inspection to ensure compliance with regulatory requirements, regulate nuclear radiation and waste safety in the country and to promote human resources development in radiation safety by promoting training of regulatory staff and organizing training courses for registrants and/or licensees. The RPB attained Institute status in the year 2002 (GAEC, 2016). 
The Biotechnology and Nuclear Agriculture Research Institute: The Biotechnology and Nuclear Agriculture Research Institute (BNARI) was established in its present form in September, 1993. Prior to that, it existed as the Department of Biology, Food and Agriculture in the National Nuclear Research Institute (NNRI), then the only institute of the Ghana Atomic Energy Commission. Since then it has developed to be the nation's leading research and development institution in nuclear science and technology covering nuclear agriculture and biotechnology. Its mandate is the efficient exploration of scientific knowledge and peaceful applications of nuclear energy and modern biotechnology for the improvement of agricultural production in furtherance of socio-economic development and national efforts to improve quality of life (GAEC, 2016).

The National Nuclear Research Institute: The National Nuclear Research Institute (NNRI), the oldest and the biggest research institute in the Commission, was established by an act of Parliament, Act 204, which also set-up the Ghana Atomic Energy Commission in 1963. The responsibilities of the Institute were spelt out in detail in Section 8 of the said Act. These responsibilities are: the supervision and control of the buildings of any nuclear installation established by or on behalf of the Commission, the supervision and the administration of the operation of any such installation, the promotion, in conjunction with the Universities, of advanced specialized teaching of and training in nuclear science and technology, securing close cooperation between the GAEC and the universities in their teaching of and research into the peaceful uses of atomic energy and promoting and maintaining close co-operation between the institute and other research or industrial bodies concerned with such teaching and research (GAEC, 2016).

The Research Reactor: It took thirty-four long years to have this dream of Ghana acquiring a research reactor fulfilled, and this was made possible through China's extra-budgetary contributions to the IAEA for the support of the Reactor Project. Thus, the IAEA provided more than one million US dollars towards the purchasing of this Chinese reactor as well as training of staff and provision of expert services. The Government of Ghana contributed two hundred thousand US dollars towards the purchasing of the reactor and also provided the infrastructure to house the machine at a cost of five hundred million cedis (GAEC, 2016). The commissioning of the reactor, named as Ghana Research Reactor-1 (GHARR-1), was performed on 8th March, 1995 by a member of the Council of State, the Honorable Nana Kojo Esuanti. The occasion attracted important dignitaries and personalities such as Dr. Hans Blix, the Director-General of IAEA, Dr. Qian Ji-hui, the Deputy Director-General, Technical Co-operation Department of the IAEA, Mr. Chen Shi-qiu, Chinese Ambassador to Austria, Dr. Christiana Amoako-Nuamah, Honorable Minister of Environment, Science and Technology and other Government Officials and members of the Diplomatic Corps (GAEC, 2016).

The GHARR-1 facility is a tank-in-pool type, light water research reactor. It is cooled by natural convection. The core is reflected on all sides with beryllium alloy. The reactor core is heavily moderated to enhance its excellent inherent safety features. The reactor was designed mainly for neutron activation analysis, and production of short-and medium-lived radioisotopes for radio-tracer studies and applications. It is also used for training and educational purposes. For maximum utilization of the reactor, the Commission established a new centre called Research Reactor Centre under the NNRI to conduct research and promote commercialization. Dr. E.H.K. Akaho was subsequently appointed the Manager of the newly created Centre.

The Gamma Irradiation Facility: In 1976, the first Head of the Department of Biology, Food and Agriculture (DBFA), the late Dr. I.K.A. Amuh started the Gamma Irradiation Project under the IAEA TC Agreement. The IAEA was to provide the Gamma Source, expert services and training. The construction of the DBFA building complex which included the housing for the Gamma Irradiator was started in 1978, but was abandoned at the foundation level due to lack of funds (GAEC, 2016). Meanwhile, personnel from the DBFA were trained by the IAEA. Using the major tool, Gamma cell 220 for laboratory-scale studies, scientists in the department carried out research on Food Irradiation, Mutation Breeding and Control of Riverine Tsetse using Sterile Insect Technique. A comprehensive programme was drawn for the Food Irradiation from the laboratory through Pilot-scale to Commercialization. Adherence to the programme led to the following achievements: identification of food commodities and non-food items which could benefit from radiation processing for preservation and microbiological safety, determination of effective irradiation dose for specific agricultural produce and product, identification of suitable packaging materials and determination of storage conditions for irradiation of commodities, public education on radiation preservation and sterilization of medical supplies, identification of potential users of radiation processing technology (GAEC, 2016). 
The above research achievements justified pilot/semi-commercial scale studies. Therefore, the use of a pilotscale gamma irradiator was revisited. The installation of the GIF was completed in 1994 and commissioned on 8th March, 1995 along with the Research Reactor. The contribution of the Ghana Government was about Three Hundred Million Cedis in the form of local inputs whilst the IAEA paid for equipment, training and foreign exchange component of the facility totaling about Two Hundred Thousand US dollars. The facility does not introduce any environmental hazard in any form, even in an accident situation. It is the Type IV irradiation facility, stored in a water pool of depth 5.7 meters. In its exposed position, the centre of symmetry of the source cage is $80 \mathrm{~cm}$. From the floor, it is shielded with concrete wall of 1.7 meters thickness. The water and concrete shields attenuate the dose rate below the recommended $2 \mu \mathrm{Sv} / \mathrm{h}$ (GAEC, 2016). This multipurpose Hungarian facility is being used for the sterilization of pharmaceutical products, preservation of food, and the processing of materials like plastics and wood and treatment of insects for pests and vector control using the Sterile Insect Technique (SIT). The Commission therefore, established a new Centre called Radiation Technology Centre (RTC) under the NNRI to run the Gamma Irradiation Facility (GIF). The establishment of the facility enhanced Research and Development, and facilitated pilot scale studies and commercialization of Radiation Processing. Mr. G. Emi-Reynolds was subsequently appointed the Manager of the RTC. In the sterilization of pharmaceutical products, highly energetic gamma rays are used to kill all the micro-organisms in the products, thus rendering them free from any harmful micro-organisms.

The Establishment of the Health Physics and The Radioactive Waste Management Centre (HPRWC): The Health Physics and Radioactive Waste Management Centre (HPRWC) was established in June, 1995 to engage in the management of radioactive waste and health physics operation at the Commission and in the nation. It has the mandate to operate a radioactive waste facility for Ghana, to help waste generators to manage their wastes, that is, treat, store and transport to the Waste Management Centre at the GAEC for conditioning, storage and final disposal and to help users of ionizing radiations to translate the Regulations and Guides of the RPB into practice (GAEC, 2016).

The Establishment of the National Centre for Mathematical Sciences: The National Centre for Mathematical Sciences (NCMS) was established by the Ghana Atomic Energy Commission in 1995 and was officially inaugurated on 10th July, 1995 by Nana Kojo Esuanti IV, a member of the Council of State. The main aim was the provision of infrastructure for research, training and education in mathematical sciences which could be available to the staff of the Commission and to other Ghanaians. Prof. F.K.A. Allotey, the Chairman of the Commission and the prime mover of the NCMS, became the Honorary Director of the Centre. The functions of the Centre were as follows: to advise the Ghana Atomic Energy Commission on policy matters with regard to development and promotion of mathematical sciences as related to the peaceful uses of nuclear energy, to establish strong links with Departments of Mathematics, Physics, Statistics and Computer Sciences in Ghanaian Universities and other research institutions, to co-ordinate mathematical research and provision of training for undergraduate and postgraduate students, to host mathematicians (not only Ghanaians) at the Centre for Seminars, workshops, conferences and sabbatical and long-term residence, to foster interaction with policy makers on matters relating to mathematics and its promotion and applications and to provide continuing education in mathematics at the pre-tertiary levels (GAEC, 2016).

The Commission and its New Parliamentary Act: As a result of the challenge thrown to the Commission by the sector Minister during his familiarization visit in February 1999, the Commission, in its anxiety to ensure that GAEC gets a viable mandate to support its developmental agenda, passionately requested the Government to speedily enact the new Commission's Bill into an Act. The Commission also formulated the following Vision and Mission statements to befit the anticipated new Act (GAEC, 2016):

GAEC Vision: To enhance the strategies for the realization of the aspirations envisaged in Ghana's developmental goal of transforming Ghana's economy to the status of a middle-level income country by the year 2020 through the peaceful uses of atomic energy and modern biotechnology. To be ready by the year 2015 to introduce nuclear power for electricity generation in Ghana for energy security and economic and social development for improved quality of life (GAEC, 2016).

GAEC Mission Statement: To co-ordinate and promote research into peaceful and safe application of Nuclear Science and Technology and Biotechnology in sectors such as health, agriculture, industry, environment and 
energy. To develop, commercialize and operate a portfolio of profitable business opportunities within GAEC's core competencies of nuclear techniques and radiation technology with the support of mechanical and system engineering capability (GAEC, 2016).

International Relations: GAEC's programs and activities are supported by several international agencies and bodies like the IAEA, UNDP, FAO, International Institute of Tropical Agriculture (ITA), International Development Agency (IDA) and World Association of Industrial and Technological Research Organization (WAITR0). The IAEA has been a major source for technical and financial support as well as manpower development. In the wake of Government policy shift to commercialization, it would be prudent to still look at the IAEA as a strategic partner to promote the peaceful utilization of nuclear technologies for socio-economic development of Ghana. GAEC is a member of African Regional Co-operative Agreement (ARCA), a regional body established in 1990 under the umbrella of the IAEA for research, development and training relevant to nuclear science and technology (GAEC, 2016).

\section{Ghana's Nuclear Power Program}

As part of plans to successfully implement a nuclear power programme, Ghana requested an Integrated Nuclear Infrastructure Review (INIR) Mission in December 2015 and submitted a Self-Evaluation Report (SER) to the International Atomic Energy Agency (IAEA) in March 2016. The main objective of the INIR mission is to assist Ghana to evaluate and determine the current status of the implementation of the nation's nuclear power programme by reviewing the nineteen infrastructure issues for phase 1 of the programme based on the evaluation conditions prescribed by the IAEA (Nyadroh, 2017). Ghana has outlined a 3-phase, 3milestone approach to the implementation of the Nuclear Power Programme in Ghana. The milestone approach involves the nineteen nuclear infrastructure development issues any newcomer country to nuclear energy must adhere to. The first phase involves: the considerations before a decision to launch a nuclear power programme (milestone 1) and the readiness to make a knowledgeable commitment to a nuclear programme, phase two involves: the preparatory work for the construction of a nuclear power plant after a policy decision has been taken (milestone 2) and invitation for bids for the first nuclear power plant, phase three will involve: the activities to implement a first nuclear power plant (milestone 3) and be ready to commission and operate the first nuclear power plant (Nyadroh, 2017). The nineteen infrastructural issues every newcomer country is expected to fulfill are: national position, nuclear safety, management, funding and financing, legislative framework, safeguards, regulatory framework, radiation protection, electrical grid, human resources development, stakeholder involvement, site and supporting facilities, environmental protection, emergency planning, security and physical protection, nuclear fuel cycle, radioactive waste, industrial involvement and procurement (Kwakye, 2017).

Ghana's quest to use nuclear science and technology for peaceful purposes including power generation dates far back in the 1960s. Realizing the significant benefits of nuclear science and technology in fostering national development, the Government of Ghana in 1961, decided to undertake the "Ghana Nuclear Reactor Project (GNRP)." The short-term objective of the project was solely for research, training and production of radioisotopes. In the long-term however, the project was to facilitate the development of manpower and promote plans for the introduction of nuclear power for electricity generation in the country (GNPPO, 2017). The programme was however halted following the overthrow of Ghana's first President in 1966 and very little was done to revisit this noble quest for stable and steady development until the severe electricity shortages of 1998 and 2007. More than fifty years after the relegation of the first president's vision to the background, Ghana's quest for industrial revolution and rapid economic growth is now threatened by huge energy deficit and insecurity of electricity supply. In 2007, a Presidential Committee was set up to advice Government on the potential use of nuclear energy for power generation in Ghana. This set the tone for revisiting the nuclear agenda. The committee in their report noted the following; that a decision by Ghana to acquire nuclear power technology will be a natural progression in the country's technological advancement and that the introduction of nuclear power in Ghana's fuel supply mix will improve the security of meeting future electricity needs of the country and thereby play a vital role in sustaining the energy requirements of a middle income economy (GNPPO, 2017). 
The committee that was set up to report on Ghana's nuclear potential submitted its report to Government after five to six months of work, which was presented to parliament and then cabinet took a decision in early 2008 and gave it the go ahead (Watson, 2017). The committee made the following recommendations in its report; setting up of a Presidential Commission on Nuclear Power Development (PCNPD) to prepare a draft Nuclear Power Policy and Terms of Reference for the additional work needed for a Technical and Financial feasibility study with a programme and time frame for action, the establishment of a legal framework and regulatory body for the regulation and enforcement of technical standards for nuclear safety and radiological protection and accidence to international agreements related to non-proliferation, physical protection, nuclear safety and security as well as a civil liability regime. Following the report and recommendations of the committee, a decision was taken to include nuclear energy into Ghana's energy mix. To realize this objective, the Ghana Nuclear Power Programme Organization (GNPPO) was constituted and inaugurated on 27th September 2012. The GNPPO is an organization mandated by the Government of Ghana to develop, implement and manage Ghana's nuclear energy programme by adopting international best practices. The GNPPO is headquartered at the Ministry of Power (GNPPO, 2017). The GNPPO is chaired by the deputy Minister of Energy under the Ministry of Energy, the vice chairman is the director-general of the Ghana Atomic Energy Commission (GAEC), who is an advisor to the Government on all nuclear energy issues including CEOs of other related institutions like the Volta River Authority (VRA). GAEC in 2014 set up a Nuclear Power Centre (NPC) to give technical advice to the board. It became the Nuclear Power Institute (NPI) in 2015. The NPI is a development institution and the lead technical power in Ghana's nuclear power programme (Watson, 2017). A Nuclear Power Programme is a major undertaking requiring investments in time, finances, institutions and human resources. The IAEA Milestone's Approach is an internationally accepted method to sustainably implement a nuclear power programme. Ghana is following the Milestone Approach which considers the programme development across three phases to achieve three respective Milestones.

Phase 1: considerations before a decision to launch a Nuclear Power Programme is taken. The embarking Country at this Phase is to make planning and preparations to satisfactorily address all the nineteen infrastructural issues. This is to be culminated into a national nuclear programme comprehensive study based on which a knowledgeable decision to implement a nuclear project can be taken.

Phase 2: preparatory work for the contracting of a Nuclear Power Plant after a policy decision has been taken. The country at this Phase, has decided that a safe nuclear power project is feasible. It therefore prepares a business justification and bankability for implementation. During this stage, the country implements most of the planning activities done in Phase 1.

Phase 3: activities to implement the first Nuclear Power Plant. Phase 3 is where the actual construction to plant commissioning usually take place. The term "Infrastructure Milestone" is used to identify the successful completion of activities under a particular phase. A decision to move to another phase is determined by the milestones. Generally, Phases 1 to 3 takes 10 to 15 years for new embarking countries (GNPPO, 2016).

Legislative Framework: Legal framework is one of the nineteen infrastructure issues to be addressed by newcomer countries for a successful implementation of a Nuclear Power Programme. A fundamental understanding of the requirements for a legal framework is therefore necessary to the GNPPO and other governmental institutions involved in the Nuclear Power Programme. The purpose of a legal framework is to develop a national legislation that would comprehensively cover all aspects of nuclear law (that is, nuclear safety, nuclear security, safeguards and civil liability for nuclear damage) and regulations. In addition, the legislation should implement international legal instruments to which the country is a party or intends to become a party (GNPPO, 2016). It is necessary to establish a national legislative framework because it addresses, the safety principle (prevention and protection), the security principle (peaceful use of nuclear power), the responsibility principle (operator or license), the permission principle (review and authorization by regulatory body), the continuous control principle (right of inspection and access by the regulatory body), the compensation principle (extent of nuclear liability), the sustainable development principle (protection of future), the compliance principle (international and transboundary agreements, treaties and conventions), the independence principle (separation of regulatory body from nuclear implementation organization), the predictability and transparency principle (clarity of the process and availability of information on all aspects of nuclear power to the applicants and to the public) (GNPPO, 2016). 
National Position: A decision to embark on a Nuclear Power Programme should be based upon a welldefined and knowledgeable national position, which is one of the nineteen infrastructural issues to be addressed by countries that opt to undertake a nuclear programme (GNPPO, 2016). Every power programme requires major investment in time, human and financial resources. Nuclear Power has additional issues involving nuclear safety, security and safeguards. An interested country should, therefore, be prepared to answer key questions and to communicate that information in a clear transparent manner. Initial discussion usually centre on the available sources of energy and the general assessment of energy demand and supply, thus the first criteria for a newcomer country embarking on a nuclear power programme is for the government to show commitment to the programme (GNPPO, 2016). A national position must provide the foundation for future development and implementation of the nuclear power programme. Most importantly, a national position provides a credible answer to the question of why nuclear power is being chosen, while taking into account the results of long-term energy planning and national priorities such as energy security, pollution mitigation including the mitigation of greenhouse gases, industrial and economic development (GNPPO, 2016).

Management: Ghana is making efforts to become a high-income country and an energy hub in the West African sub-region. A major driver to this ambition is the availability of efficient, affordable, reliable and environmentally friendly energy. The country is therefore taking systematic steps to include nuclear energy in its energy mix because nuclear technology promises to yield such type of energy (GNPPO, 2016). An important step towards the inclusion of nuclear energy is that the country has developed a roadmap that follows the International Atomic Energy Agency's (IAEA) three-phase model for the development of a nuclear power programme. Management is one of the infrastructural issues. Efficient management is the bedrock for a successful execution of any project. In the nuclear industry, human and environmental safety is the utmost priority. Sound management, leadership and strong safety culture are needed to prevent and deal with any threat on safety. The management system provides the framework for the effective management of a nuclear power programme by ensuring that the available resources are well organized and applied efficiently to achieve the best outcome. Rules and responsibilities of management of the Ghana nuclear power programme will change as the process progresses from study to implementation to operation and decommissioning. Highly competent managers are therefore vital to the success of the Ghana nuclear power programme at all stages. The goal of the GNPPO as a management body of Ghana's nuclear power programme is to ensure an effective management that entails commitment to leadership and management systems, project management, strategy and planning, organization and competence development (GNPPO, 2016). After the country is able to satisfy the nineteen issues then the international community is sure the project is safe and safeguarded from malicious use or intent. The country has also made provisions for spent fuel; either recycled or cooled (Watson, 2017).

\section{The Role of Nuclear Energy in the Development of Countries}

Nuclear Power is unique as very large amount of energy is generated from a very small amount of fuel (Badu, 2013). One peacetime application of nuclear energy is its use as a source of power. In the beginning, at least, this development will serve to supplement our existing sources of energy. Ultimately, nuclear energy may supplement entirely our present sources (Nickson and Brown, 1947). One of the most important immediate applications of nuclear energy and its by-products will be the solution of problems in biology and medicine (Nickson and Brown, 1947). According to Dr. Daniel Watson, countries which adopted nuclear energy in their energy mix has their Gross Domestic Product (GDP) shoot up due to the stable power supply that came with it. Nuclear power is stable, reliable and helps companies thrive owing to the stable power. Also, except for the cost of setting up nuclear plants, operating and maintaining, it is relatively cheaper as compared to other sources of electricity (Watson, 2017). Although opposition to nuclear energy is prominent in United States among the political left, reasonable liberals are realizing that increased use of nuclear energy will reduce the emissions linked to climate change. As an article in Wired magazine put it, "some of the world's most thoughtful greens have discovered the logic of nuclear power"- logic suggesting that "a clean, green future" can be reached if we "start building nuke plants and keep building them at a furious pace (Center for the Study of Technology and Society, 2005)." 
Nigeria hopes to become one of the twenty biggest economies in the world by 2020 in its "Vision 2020" plan. Also, in order for Nigeria to meet its Millennium Development Goals of being energy sufficient, the Nigerian government has revisited its earlier nuclear power programme in order to achieve this target and clamp down on the erratic power supply the country continues to face (Lowbeer-Lewis, 2011). Global warming has become a great source of worry to many countries across the world, due to the adverse effects on especially agriculture. There is a pursuit for international energy security where countries are looking for alternative sources to fossil fuels and coal which have high carbon emission rates compared to lower carbon emission sources of power. Nuclear power offers energy-hungry developing nations the access to large-scale reliable base load electricity supplies, with very low carbon emissions (Jackson, 1944). According to Dr. Nils J. Diaz, "safe nuclear energy is good for the nation and good for the world. And the future is bright for those who choose to pursue careers in the field (Diaz, 2003)." Dr. Nils J. Diaz believes that with abundant and economical energy, it is possible to provide the food, water, hygiene, environment and quality of life essential to the dignity and well-being of every human. Nuclear energy, safe and abundant, is and should be an important part of such a bright future and those who choose engineering careers in the field can count on bright futures, too (Diaz, 2003).

Advocates of nuclear power cite its clean energy- that nuclear power plants do not emit carbon dioxide, Sulphur dioxide or nitrogen oxides. Huge amounts of electricity can be generated in a relatively small space with less land than other energy sources. One uranium fuel pellet contains the same amount of energy as 17,000 cubic feet of natural gas, 1,780 pounds of coal, or 149 gallons of oil. Nuclear waste is small in physical size compared to waste produced by other forms of energy. Electricity from a nuclear power plant is available when needed and not dependent on the wind or the Sun. The water that is discharged from power plants is relatively clean and not radioactive. Some sources also cite benefits such as state and tax revenues and the potential to develop wetlands around a power plant (Palliser, 2012). The beauty of nuclear fission is its ability to derive so much from so little. The energy density of nuclear fuel far exceeds that of any other energy source. As Peter Huber states, "a bundle of enriched-uranium fuel rods that could fit into a two-bedroom apartment in Hell's Kitchen would power (New York City) for a year: furnaces, espresso machines, subways, streetlights, stock tickers, Times Square, everything- even our cars and taxis, if we could conveniently plug them into the grid (Schulz, 2006).

Safety Concerns: Many Ghanaians are concerned about Ghana adopting nuclear energy into its energy mix, because they are skeptical about Government and the Ghana Atomic Energy Commission's readiness to manage the waste from nuclear plants which can be harmful to the people. Risks are associated with a lot of these. However, the risks involved with nuclear power did not deter the developed countries from opting for it (Klutse, 2016). In Africa, nuclear energy production invokes so much fear in people such that governments have had to abandon these projects irrespective of the numerous benefits these countries stand to gain from it. Dr. Nana Ama Klutse Browne argues that some of the concerns regarding nuclear power are misconceptions and exaggerations largely fuelled by international politics (Klutse, 2016). Concerns have been raised about the safety of the global expansion of nuclear energy. These concerns are embedded in the belief that nuclear energy is instrumental in the proliferation of nuclear weapons. It is also believed that there are about 20,000 nuclear weapons in the world and countries with such fire-power see this as a source of power and prestige which they can unleash on any one they may deem as an enemy. This has sparked some fear of an imminent nuclear war among people worldwide (Socolow and Glaser, 2009). For the past fifty years of commercial nuclear plants operation, there have been serious accidents, yet the safety record of existing nuclear plants has improved over time as safety precautions regarding nuclear energy has been strictly observed and upgraded. Nuclear energy is unsafe in environments of complacency and the desire to maximize profits over the safety of the environment (Walls and Harrison, 2011).

Einstein is of the view that the "dangers of destructive power of nuclear energy are so vast that a new way of thinking is necessary if we want to survive (Šahović, 1965)." According to Dr. Watson, the production and proliferation of nuclear weapons gave rise to strict regulations on nuclear energy production as well as generating electricity through nuclear energy. Any newcomer country wanting to adopt nuclear energy to generate electricity goes through some nineteen regulations which is strictly monitored by the International Atomic Energy Agency (IAEA) before it is finally cleared to operate the plant. Again, while operating the plant, it is still monitored to prevent any accidents (Watson, 2017). No new nuclear plants were ordered in the 
United States since the 1970 s and today it has only 104 reactors, largely due to fears of a nuclear accident in the wake of the Three Mile Island and Chernobyl (Center for the Study of Technology and Society, 2005). The Seabrook nuclear power plant in New Hampshire was proposed in 1968 for completion in the mid-1970s. However, anti-nuclear protesters hampered its construction. There were several other protests of such nature all aimed at preventing the project from being carried out. It was finally completed in 1986. Before that, a group calling itself "Food Not Bombs" attempted to occupy the Seabrook plant as a way of opposing the project (Center for the Study of Technology and Society, 2005). Significantly, in Netherlands, the Social and Economic Council advised the Dutch government to suspend further plans on increasing the country's nuclear generating capacity until 2010. It suggested that the government should keep an open mind about the use of nuclear energy in the Netherlands (de Groot et al., 2010).

Nuclear energy though will serve as a solution to climate change. There is a price to pay: the risk of nuclear energy technology and nuclear materials being diverted and weaponized to fabricate military atomic weapons. The tension in the Persian Gulf which involves Iran and the United Arab Emirates also raises concerns as these countries are also developing nuclear energy technology, with Iran going ahead to begin what the international community deems is a move to develop nuclear weapons (Jackson, 1944). Since the terrorist attacks of September 11, 2001, concerns have been raised about the United States' 103 nuclear plants as likely to experience a terrorist attack in the coming years. This led to a heightened state of alert at all nuclear plants in the country. Nuclear plants security forces were deployed at all facilities. A legislation was also passed by the House of Representatives to revise the security requirements of the Nuclear Regulatory Commission (NRC). Again, anti-aircraft weapons were installed and a permanent "no fly" zone was created around them (Gaukler et al., 2002).

\section{Conclusion}

Nuclear energy in Ghana is as old as Ghana's republican status as it was during this period that the country in its industrialization drive sought to opt for nuclear power to augment the already existing hydroelectric dam project at Akosombo. However, this plan was cut short when the nation's first government was toppled in a military coup d'état. The country since then has been going back and forth with its nuclear plants with successive governments making very little contributions. Nuclear energy for electricity generation is becoming a stronger case as an alternative energy source, especially when compelling arguments are also made for solar energy. Our electricity situation is alarming because we are not generating enough with Hydro from Akosombo and Kpong which is producing roughly $1180 \mathrm{MW}$ and Thermal producing $1005.5 \mathrm{MW}$ which total as 2185.5 MW installed capacity of electricity (Nyadroh, 2017). The country's effort to utilize nuclear energy dates back to the early 1960s. In 1961, the government initiated the Kwabenya Nuclear Reactor Project as a means of introducing nuclear science and technology into the country and to exploit nuclear energy in its peaceful applications for the solution of problems of national development (Ennison and Dzobo, 2017). The Ghana Atomic Energy Committee was set up to implement the Kwabenya Nuclear Reactor Project. This committee was later replaced by the Ghana Atomic Energy Commission (GAEC) by an Act of Parliament in 1963. The research reactor project involved the construction of a $2 \mathrm{MW}$ Soviet reactor for the production of isotopes as well as training the requisite manpower for reactor operations and research into nuclear science and technology (Ennison and Dzobo, 2017).

The Ghana Atomic Energy Commission Act set out the direction in which the future development of atomic energy in Ghana shall take. The Government under the National Liberation Council (NLC) negotiated with the Government of the United Soviet Socialist Republics (USSR), in an agreement to build in Ghana a research thermal reactor of the Swimming Pool type (Public Records and Archival Department of Ghana, 1966). Training of personnel to operate the research reactor began in September 1962 with the first batch of twenty trainees sent to the Soviet Union, for duration of eighteen months. Under the terms of the agreement covering the Reactor Project, specialists from the Soviet Union were available to work at the Institute for a specified period (Public Records and Archival Department of Ghana, 1966). Though such progress was made in acquiring a research reactor for the country, the entire nuclear project as envisioned by Dr. Kwame Nkrumah was abandoned, when the NLC government invited a British consulting firm led by John Cockcroft who said the country will not need this amount of energy for the next twenty years, citing the strength or size of Ghana's economy (Watson, 2017). The country, after the energy crisis in 2007, took a critical look at nuclear 
energy salvaging the situation. There was a shortfall of about 400MW in power supply from the hydro system. The import bill of crude oil soared due to high price on the international market and the supply of gas from Nigeria delayed. The then President John Kufuor in May 2007 set up an eight-member committee to advise government on the potential use of nuclear energy for electricity generation and develop a roadmap, which must culminate in a pre-feasibility study. After its assessment, the committee concluded that since nuclear energy is a mature technology which has witnessed significant improvements in economic performance and operational safety in recent years, it is capable of providing safe, reliable and economically competitive electricity with very low carbon emissions. A roadmap was developed, which proposed the formation of Presidential Commission on Nuclear Power Development and a 400 MW nuclear Power plant to start commercial operation in 2018. A cabinet decision was taken in early 2008 to proceed with the roadmap (Ennison and Dzobo, 2017).

The country has since then made efforts to arrive at this plan of involving nuclear energy into its energy mix. The country is working closely with the International Atomic Energy Agency (IAEA) to fulfill this plan. The country is adhering to all the nineteen issues that comes with a newcomer country wanting to go nuclear: issues like a national position, nuclear safety, management, funding and financing, legislative framework, safeguards, regulatory framework, radiation protection, electrical grid, human resources development, stakeholder involvement, site and supporting facilities, environmental protection, emergency planning, security and physical protection, nuclear fuel cycle, radioactive waste, industrial involvement and procurement. Electricity supply security is a pre-requisite for industrialization, sustainable development and improvement in social well-being and therefore it must be a key policy agenda for the government. In order for Ghana to attain high levels of economic growth and social well-being in the future, electricity consumption and production will have to increase significantly. The current and future primary energy supply potential for the country cannot guarantee this magnitude of future electricity demand and supply unless nuclear energy is considered and a comprehensive long term primary energy supply strategy developed to ensure the availability and accessibility of primary energy at affordable prices. Nuclear power is therefore expected to play a critical role in the sustainable development of the country as well as meeting the millennium development goals. There are however challenges in the deployment of nuclear power for electricity generation in the country. The future deployment of nuclear power therefore requires comprehensive planning and development of an appropriate implementation strategy (Ennison and Dzobo, 2017).

Ghana stands to gain a lot if it adopts nuclear power into its energy mix. If Ghana wants to achieve sustainable development, it should not drag its feet at this project. Nuclear power is known to produce much power with just a little uranium fuel which will encourage the growth of industries and promote foreign direct investment due to the stable power it will bring. The concern over nuclear energy is radioactive, this is known to be dangerous and a legitimate concern, yet it did not deter France from adopting it into its energy mix. France's electricity is primarily from nuclear sources and arguably the country in Europe with the highest percentage in nuclear power generation. The Chinese are also looking to boost their economy and control of the world's market with nuclear energy as their main source of electricity. Ghana can learn from these countries and make use of the nuclear resources it has including the human resource it had spent its resources to train and equip for the nuclear power project.

\section{References}

Amuzu, J. K. A. (2016). The Nuclear Option for Ghana, available at https://books.google.com.ghj.k.a.+amuzu.+the+nuclear+option+for+ghana, (Accessed 10 February 2016).

Badu, J. (2013). Options for Addressing Ghana's Electricity Shortfall and Case against Nuclear Power, 1-18.

Bannor, A. W. N. Q. (2014). Ghana's Statement at the 58th Regular Session of the IAEA General Conference, Vienna, Austria, 1-6.

Beckrich, A. (2013). The Green Room: The Pros and Cons of Nuclear Energy. The Science Teacher, 80(3), 10.

Birikorang, S. A., Gbadago, J. K., Akaho, E. H. K., Nyarko, B. J. B., Amoako-Amponsah, E., Odoi, H. C., Abrefah, R. G., Debrah, S. K., Sogbgaji, R. B. M., Boafo, E. \& Boffie, J. (2012).Prospects of Nuclear Power Today as Part of Ghana's Energy Mix and Socio-Economic Development. Department of Nuclear Engineering and Material Science, School of Nuclear and Allied Sciences, 2, 67-76. 
Bose, D. K. (1981). Accounting of Nuclear Power. Economic and Political Weekly, 16(32), 1313-1318.

Boussaha, A., McDonald, A. \& Hans-Holger, R. (2007). Plan 'A' for Africa. IAEA Bulletin, 49(1), 36-39.

Bratt, D. (2005). Implementing Kyoto in Canada: The Role of Nuclear Power. The Energy Journal, 26(1), 107121.

Center for the Study of Technology and Society. (2016). Is Nuclear Energy Coming Back? The New Atlantis, 8, 119.

Comby, B. (2006). The Benefits of Nuclear Energy, 1 \& 3.

Dadzie, I. K. (2016). Nuclear Energy for Ghana: A Must and Urgent Need for the People, Centre for Conscientist Studies and Analyses, available at https://consciencism.wordpress.com/history/nuclear-energy-forghana, (Accessed 10 February 2016).

De Groot-Judith, I. M., Steg, L. \& Poortinga, W. (2013). Values, Perceived Risks and Benefits. Acceptability of Nuclear Energy, 33(2), 307-317.

De Groot-Judith, I. M. \& Steg, L. (2010). Morality and Nuclear Energy: Perceptions of Risks and Benefits, Personal Norms and Willingness to Take Action Related to Nuclear Energy. Risk Analysis, 30(9), 1363-1373.

Diaz, N. J. (2003). Nuclear Energy for the Future. Hispanic Engineer and Information Technology, 18(1), 8.

Ennison, I. \& Dzobo, M. (2017). Nuclear Power and Ghana's Future Electricity Generation. National Nuclear Research Institute, IAEA-CN-164-IP01: 1-7, available at, https://www.google.com.gh/search?q=++I.+Ennison+and+M.+Dzobo\%2C+"Nuclear+Power+and+Gh ana's+Future+Electricity+Generation, (Accessed 24 August 2017).

Feiveson, H. A. (2009). A skeptic's view of nuclear energy. Daedalus, 138(4), 60-70.

Gaukler, P., Barnett, S. D. \& Rosinski, D. J. (2002). Nuclear Energy and Terrorism. Natural Resources and Environment, 16(3), 165-171.

Gawusu, S. (2016). Combating Climate Change and Energy Crisis in Ghana: The Role of Nuclear Energy, Modern Ghana, available at https://www.modernghana.com/news/combating-climate-change-andenergy-crisis.html, (Accessed 10 February 2016).

Ghana Atomic Energy Commission (GAEC). (2016). About Ghana Atomic Energy Commission", available at http://www.gaec.org/about-ghana-atomic-energy-commission, (Accessed February 8, 2016).

Ghana Atomic Energy Commission (GAEC). (2016). The History of Ghana Atomic Energy Commission: Forty Years of Nuclear Science and Technology Applications in Ghana. Accra, (1963-2003).

Ghana News Agency (GNA). (2016). Ghana Makes Progress towards Nuclear Power Plant. (27 February 2016): $1-2$.

Ghana Nuclear Power Program Organization (GNPPO). (2017). Our History, available at www.gnppo.org/about-us/our-history, (Accessed April 1, 2017).

GNPPO. (2016). Approach to Developing the Required Infrastructure for Ghana's Nuclear Power Programme, GNPPO News (June 2016), available at www.gnppo.org/images/june.jpg, (Accessed April 2, 2017).

GNPPO. (2016). Legislative Framework, GNPPO Newsletter, (July 2016), available at www.gnppo.org/images/july.jpg, (Accessed April 2, 2017).

GNPPO. (2016). Management, GNPPO Newsletter, (September 2016), available at www.gnppo.org/images/september.jpg, (Accessed April 2, 2017).

GNPPO. (2016). National Position, GNPPO Newsletter, (August 2016), available at www.gnppo.org/images/august.jpg, (Accessed April 2, 2017).

Grandin, K., Jagers, P. \& Kullander, S. (2010). Nuclear Energy. Royal Swedish Academy of Sciences, 39, 26-30.

Hubert, K. M. (1956). Nuclear Energy and the Fossil Fuels. American Petroleum Institute, 95, 1-57.

Institute of Applied Science. (2016). Atomic Energy", available at http://www.ias.unt.edu/ waller/renewable_energy/download/atomicenergy.ppt, (Accessed 10 February 2016).

Jackson, I. (1944). Nuclear Energy and Proliferation Risks: Myths and Realities in the Persian Gulf. International Affairs (Royal Institute of International Affairs, 85(6), 1157-1172.

Klutse, B. N. A. (2016). Adding Nuclear Power to Ghana's Energy Mix", available at www.ghanabizfinance.com/adding-nuclear-power-to-ghanas-energy-mix, (Accessed 9 February 2016).

Kwakye, R. (2017). Ghana's Implementation Approach, available at www.gnppo.org/newsevents/publications/milestone-approach/ghana-s-npp-implementation-approach, (Accessed April 1, 2017). 
Ledoshchuk, B. (2016). What We Know About Nuclear Energy, (Lectures, Supercourse, International Editorial Board, Kiev, Ukraine), available at http://www.pitt.edu/ super4/37011-38001/37401.ppt, (Accessed February 9, 2016).

Lewis-Lowbeer, N. (2011). Nigeria and Nuclear Energy: Plans and Prospects." Nuclear Energy Futures, 11, 114.

Napavalley. (2016). Nuclear Energy", Chapter 12, (2011), available at http://www.napavalley.edu/people/briddell/Documents/rav7e_ch12_lecture.pdf. (Accessed 10 February 2016).

Nickson, J. J. \& Brown, H. S. (1947). Atomic Energy and Your Future. ALA Bulletin, 41(3), 71-74.

Nuclear Energy. (2016). Available at http://education.jlab.org/jsat/powerpoint/0708_nuclear_energy.ppt, (Accessed February 11, 2016).

Nuru, J. (2014). Demystifying Fears of Nuclear Energy Generation in Ghana, Modern Ghana, available at https://www.modernghana.com/news/demystifying-fears-of-nuclear-energy-generation-in.html, (Accessed February 9, 2016).

Nyadroh, S. (2017). Developing Nuclear Power in Ghana", available at www.gnppo.org/newsevents/publications/articles/developing-nuclear-power-in-ghana, (Accessed April 1, 2017).

Nyadroh, S. (2017). Ghana's NPP Implementation Approach", available at www.gnppo.org/newsevents/publications/milestone-approach/ghana-s-npp-implementation-approach, (Accessed April 1, 2017).

Nyadroh, S. (2017). INIR Mission in Accra, available at www.gnppo.org/news-events/ourprogram/events/all-is-set-for-inir-mission, (Accessed April 1, 2017).

Nyarko, B. J. B., Akaho, E. H. K. \& Ennison, I. (2009). Nuclear Power for Electricity Generation in Ghana: Issues and Challenges, 1-6.

Palliser, J. (2012). Nuclear Energy. Science Scope, 35(5), 14-18.

Public Records and Archives Department of Ghana, Accra, RG 11/1/387, section 20 of the Memorandum for Ghana Atomic Research Reactor. (1966).

Šahović, M. (1965). International Control of the Uses of Nuclear Energy. Journal of Peace Research, 2(4), 297306.

Schulz, M. (2006). Nuclear Power Is the Future. The Wilson Quarterly, 30(4), 59-63.

Socolow, R. H. \& Glaser, A. (2009). Balancing Risk: Nuclear Energy and Climate Change. Daedalus, 138(4), 3144.

U.S. Department of Energy, Office of Nuclear Energy, Science and Technology, The History of Nuclear Energy, Washington D.C. 3. https://www.energy.gov/ne/office-nuclear-energy (accessed, 22nd July, 2017)

Walls, J. \& Harrison, R. (2001). Of Nuclear Power Generation: Past, Present and Future, Nuclear Power and the Environment, (London, Royal Society of Chemistry), 1-47.

Watson, D. (2017). Interview by Adoteye Victor Nii Akwei. Accra. February 6, 2017.

Weinberg, A. M. (1980). Is Nuclear Energy Necessary? Proceedings of the American Philosophical Society, 124(6), 399-403.

Whitefield, S. C., Rosa, E. A., Dan, A. \& Dietz, T. (2009). The Future of Nuclear Power: Value Orientations and Risk Perception. Risk Analysis, 29(3), 425-437.

Wilson, P. D. (2010). Nuclear Energy. Science Progress, 93(4).

Woolbright, S. J., Schumacher, J. P. \& Michonova-Alexova, E. I. (2014). From the Dawn of Nuclear Physics to the First Atomic Bombs. Asian Journal of Physics, 23(1\&2), 1-20.

World Nuclear Association (WNA). (2016). Emerging Nuclear Energy Countries, available at www.worldnuclear.org (Accessed on Thursday 11 February 2016). 